https://journal.uwgm.ac.id/index.php/abdimasmahakam

E-ISSN: 2549-5755

Januari 2020, Vol. 4 No. 01

Received: September 2019

Accepted: Desember 2019

Published: Januari 2020

Article DOI: http://dx.doi.org/ 10.24903/jam.v4i1.805

\title{
Pemberdayaan Kader melalui Hidroponik pada Lahan Sempit sebagai Upaya Preventif Diabetes Melitus
}

\author{
Retno Yulianti \\ Universitas Pembangunan Nasional Veteran Jakarta \\ retno.yulianti@upnvj.ac.id \\ Andri Pramesyanti Pramono \\ Universitas Pembangunan Nasional Veteran Jakarta \\ apramesyanti@gmail.com \\ Bunga Nurcita \\ Universitas Pembangunan Nasional Veteran Jakarta \\ boenga.nurcita@gmail.com
}

\begin{abstract}
Abstrak
Permasalahan yang terjadi sebanyak 15 persen penduduk Depok menyandang penyakit diabetes melitus serta penyebab kematian sekitar $6.84 \%$. Kurangnya perhatian penyandang diabetes terhadap upaya preventif menanggulangi komplikasi diabetes, maka upaya yang dapat dilakukan melalui bercocok tanam dengan hidroponik meskipun memiliki pekarangan yang sempit. Tujuan kegiatan adalah agar kader Posbindu di RW 05 Kelurahan Gandul dapat meningkatkan pengetahuan, sikap dan ketrampilan, meningkatkan kesadaran masyarakat untuk memanfaatkan barang bekas sebagai upaya mengurangi keberadaan sampah plastik serta memberi pengetahuan peluang wirausaha baru dari hidroponik. Metode kegiatan adalah memberikan penyuluhan kesehatan dan pembekalan hidroponik sistem Wick, diskusi dan tanya jawab serta demonstrasi dan praktek mandiri dengan menggunakan barang bekas. Evaluasi kegiatan dengan melihat kehadiran dan antusiasme kader dalam diskusi dan praktek serta penilaian pretest dan postest. Hasil kegiatan adalah kehadiran peserta kader sebanyak 93,3\%, peningkatan pengetahuan sekitar $80 \%$ dan peningkatan sikap positif kader menjadi $92,86 \%$ dari total peserta terhadap hidroponik, antusiasme kader yang tinggi lewat interaksi pada saat praktek budidaya hidroponik, serta membuat wadah tanaman dari barang bekas. Kesimpulan kegiatan adalah para kader RW 05 telah menerapkan pemanfaatan lahan pekarangan dengan bercocok tanam, sehingga pembekalan hidroponik dapat memberikan peningkatan pengetahuan dan keterampilan budidaya sayuran dalam pot/wadah dari barang bekas dan dapat mendukung ketahanan pangan keluarga.
\end{abstract}

Kata Kunci: hidroponik; diabetes melitus. 


\section{Pendahuluan}

Berdasarkan letak geografis, Posbindu Anggrek Bulan dan Posbindu Delima Senja berada di RW 05 Kelurahan Gandul Kecamatan Cinere Kota Depok. Kelurahan Gandul memiliki luas: 289 Ha dan sebanyak 77,5\% dari total luas lahan di Desa Gandul adalah pemukiman warga (BPS Depok, 2014b). Kecamatan Cinere merupakan wilayah terkecil di Kota Depok dengan luas $10,68 \mathrm{~km}^{2}$ dan kepadatan penduduk $13.048 / \mathrm{km}^{2}$, sedangkan jumlah kepadatan penduduk di Kelurahan Gandul adalah 7012 orang / km2. Pada tahun 2013, 31.374 orang bekerja dan 11.283 orang tidak bekerja di desa Gandul (Dinas Kesehatan Depok, 2018), (BPS Depok, 2014b).
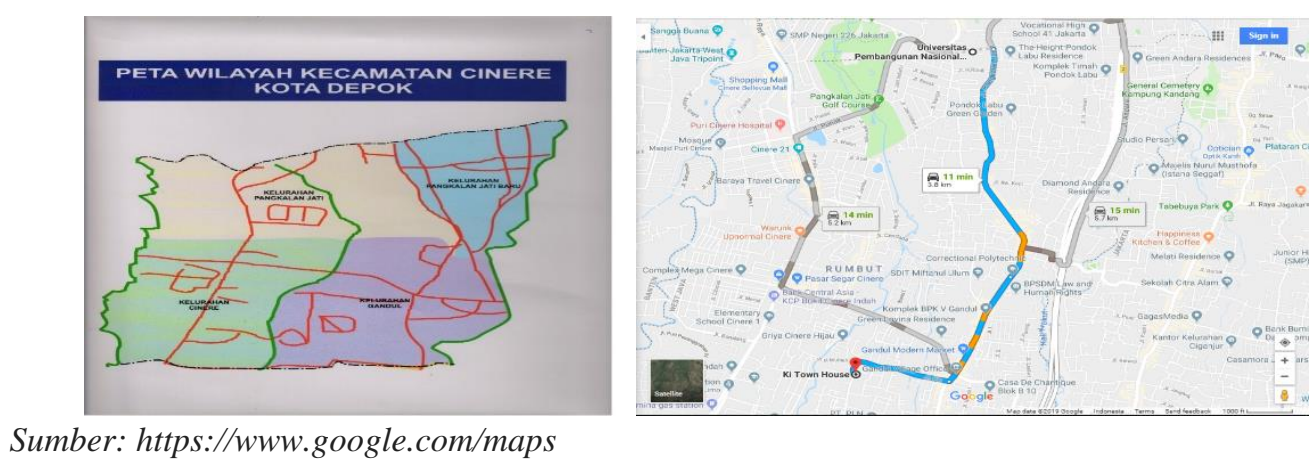

Gambar. 1 Lokasi Mitra Posbindu RW 05 Kelurahan Gandul

UMKM telah teruji dalam jangka waktu yang lama, di mana ketika krisis ekonomi melanda Indonesia pada tahun 2018, ketika perusahaan menengah hingga besar runtuh karena krisis moneter, hanya UMKM yang mampu bertahan dan bahkan lebih mampu berkembang, bahkan dalam kondisi krisis ekonomi, sampai sekarang UMKM terus berkembang dalam kemajuannya di semua bidang.

Jumlah Usaha Mikro di Kota "Tepian" hingga akhir 2017 telah mencapai 56 ribu, di mana jumlah ini telah mengalami peningkatan yang signifikan dibandingkan tahun 2016 lalu, yang hanya sebesar 302 ribu. Disperindagkop Kalimantan Timur mencatat, pada 2016, jumlah UMKM di Kalimantan Timur adalah 314.095 unit dan meningkat 1,5 persen pada 2017 menjadi 318.802 unit. UMKM telah menyerap 1.080.072 orang, dibandingkan dengan jumlah total pekerja pada tahun yang sama dengan 1.535.296 orang. Kondisi ini menunjukkan bahwa UMKM Kalimantan Timur menyerap 70,50 persen dari total tenaga kerja di Kalimantan Timur. Secara lebih rinci, pada tahun 2017, setiap unit UMKM di Kalimantan Timur menyerap rata-rata sekitar tiga pekerja. Dengan detail masing-masing bisnis skala mikro menyerap rata-rata satu hingga dua orang. Kemudian, usaha kecil tiga orang, dan usaha menengah rata-rata empat orang.

UMKM memang memiliki peran penting dalam menyerap tenaga kerja, dan membuka bidang bisnis yang cukup besar menjadi posisi tawar yang baik dalam fokus kebijakan, program, dan kegiatan politik pada tahun 2019. Memperkuat dan memberdayakan UMKM adalah salah satu masalah yang penting dalam mendorong perkembangan ekonomi Kalimantan Timur. Sehingga di tahun-tahun mendatang, diprediksi bahwa UMKM akan memiliki peluang lebih besar untuk berkembang. Karena pada 2019 merupakan tahun persiapan program dan kegiatan untuk meningkatkan kemampuan UMKM Kalimantan Timur dalam Rencana Pembangunan Jangka Menengah. Masih banyak UMKM yang tidak menyadari pentingnya catatan keuangan dan akuntansi yang tepat. Padahal, dengan pembukuan bisnis, pelaku bisa 
mengetahui apakah bisnis mereka sehat atau tidak. Bahkan, di era digital saat ini, sebagian besar UMKM masih "buta" dalam akuntansi. Akibatnya, wajar bahwa banyak dari mereka tidak memiliki pembukuan dalam bisnis mereka, yang memiliki potensi untuk tumbuh. Pada saat kita berbicara tentang pertumbuhan bisnis, yang kita bicarakan adalah postur organisasi dalam bentuk angka. Sejak mulai membangun bisnis dan jika ingin bertumbuh, maka para pelaku bisnis harus menyadari angka-angka yang harus ada dalam bentuk laporan keuangan, terutama di era digital saat ini, itu harus lebih nyaman. UMKM di Indonesia telah terbukti menjadi pendorong selama terjadinya perlambatan ekonomi. UMKM telah berkontribusi 60 persen dari Produk Domestik Bruto nasional dan menyerap 97 persen tenaga kerja. Saat ini, jumlah usaha kecil di Indonesia telah mencapai 93, 4 persen, dan usaha menengah mencapai 5,1 persen, sedangkan usaha besar hanya 1 persen. Namun, jumlah itu tidak pernah bertambah. Dalam situasi dan kondisi, perlu untuk melakukan pelatihan dengan media software akuntansi untuk UMKM, terutama di sektor bisnis jasa.

Secara statistik penderita diabetes melitus (DM) di Indonesia meningkat dan berada di urutan keempat terbesar di Asia serta urutan ke tujuh dari berbagai negara di dunia. Badan Kesehatan Dunia (WHO) memperkirakan tahun 2030 terjadi peningkatan jumlah penyandang diabetes tipe 2 di Indonesia dari 8,4 juta menjadi sekitar 21,3 juta (Perkeni,2015). Kota Depok menduduki peringkat kedua terbanyak penderita diabetes melitus se-Indonesia setelah Maluku Utara. Tercatat sebanyak 15 persen penduduk Depok menderita diabetes melitus. Menurut Dinas Kesehatan Depok tahun 2017, bahwa dari seluruh rumah sakit yang ada di Kota Depok, diabetes melitus termasuk dalam pola 10 besar penyakit terbanyak pada pasien rawat jalan (11.76\%) dan rawat inap (14.5\%) serta penyebab kematian (6.84\%) (Dinkes Depok,2017). Hasil wawancara awal kepada kader didapatkan kurangnya perhatian penderita diabetes terhadap nutrisi untuk mengurangi komplikasi penyakitnya. Pengetahuan tentang nutrisi dalam tatalaksana diabetes masih rendah. Hal tersebut dikarenakan kurangnya informasi yang dimiliki penderita diabetes di sekitar Posbindu Anggrek Bulan dan Delima Senja di Kelurahan Gandul, Cinere Kota Depok serta belum adanya pelatihan bagi kader mengenai nutrisi yang tepat bagi penderita diabetes. Dengan kepadatan penduduk yang cukup tinggi dengan tingkat angka kejadian penyakit diabetes yang tinggi, maka potensi untuk pengembangan produk sayuran pada skala rumah tangga atau pekarangan cukup dapat dilakukan karena sebagian rumah penduduk memiliki halaman yang meski sempit (Roidah, I.S, 2014).

Oleh karena itu dibutuhkan suatu cara untuk dapat membangun RW 05 ini menjadi wilayah percontohan yang berkembang sebagaimana yang dimuat di dalam UU. No. 06 tahun 2014 Tentang Kelurahan/Desa, desa membawa angin segar untuk pemerintah desa saat ini.

Berdasarkan uraian tersebut mendorong tim pengabdian kepada masyarakat bertujuan untuk melakukan pemberdayakan kader posbindu dan masyarakat sekitar terutama keluarga penyandang DM melalui pengenalan teknologi hidroponik sederhana pada lahan sempit sebagai upaya preventif bagi penderita diabetes melitus, meningkatkan kesadaran masyarakat untuk memanfaatkan barang bekas sebagai upaya dalam mengurangi keberadaan sampah plastik di kehidupan masyarakat serta dapat menjadikan hidroponik sebagai wirausaha baru produk pangan bagi masyarakat sekitar.

\section{Metode}

Pelaksanaan pengabdian yaitu praktik pengolahan sari jeruk dilaksanakan di Balai Dusun 
https://journal.uwgm.ac.id/index.php/abdimasmahakam

E-ISSN: 2549-5755

Januari 2020, Vol. 4 No. 01

Sempu, Desa Gading Kulon, Kec. Dau, Kab. Malang pada hari Sabtu, 23 Maret 2019. Dihadiri oleh 42 orang yang merupakan mitra pengabdian dan semuanya berasal dari anggota kelompok tani jeruk Dusun Sempu, Gading Kulon.

Kegiatan dalam pengabdian ini berbentuk pemberdayaan kader posbindu melalui pengenalan hidroponik pada lahan sempit sebagai upaya preventif Diabetes Melitus di Kelurahan Gandul Kecamatan Cinere Kota Depok secara umum kegiatan meliputi:

\section{Observasi}

Tahap observasi bertujuan mengetahui masalah kesehatan masyarakat terutama penyakit diabetes melitus dan mengetahui kondisi lingkungan sekitar. Tempat pelaksanaan obsevasi adalah di posbindu Anggrek Bulan dan Delima Senja RW 05 Kelurahan Gandul Kecamatan Cinere Kota Depok. Dalam melakukan observasi terdapat tiga cara yang dilakukan,yaitu :

a. Observasi Lapangan: melihat data posbindu terkait jumlah penyandang DM dan komplikasi yang sudah didapatkan dari penderita serta masalah kondisi lingkungan. Pada saat observasi lapangan, kegiatan yang dilakukan hanya mengamati secara langsung keadaan lingkungan sekitar posbindu Delima Senja dan Anggrek Bulan.

b. Wawancara: dilakukan berupa kegiatan penggalian informasi terhadap masalah kesehatan terkait penyakit diabetes melitus kepada warga masyarakat secara langsung terutama pengetahuan mereka tentang nutrisi dalam menurunkan kadar gula darah. Data diambil dari hasil bertanya terhadap warga masyarakat.

c. Focus Group Discussion (FGD): dilakukan kegiatan diskusi kelompok secara terarah. Kegiatan ini dimaksudkan untuk menggali informasi sebanyak-banyaknya, juga membahas berbagai persoalan kesehatan yang terjadi di masyarakat terkait penyakit diabetes melitus dan hidroponik.

\section{Pengenalan dan Penyuluhan}

Kegiatan ini bertujuan mengenalkan segala hal mengenai penyakit diabetes melitus baik komplikasi dan nutrisi bagi penyandang DM serta mengenai teknik hidroponik sederhana juga peluang usahanya.

Kegiatan ini terbagi menjadi beberapa tahap yaitu:

a. Penyuluhan Penyakit Diabetes Mellitus

Kegiatan ini memberikan pengetahuan tentang komplikasi dan nutrisi bagi penyandang diabetes melitus. Pemberian materi dengan metode ceramah dan tanya jawab.

b. Pengenalan Teknik Hidroponik Sederhana

Kegiatan ini merupakan tahap awal menginformasikan kepada peserta mengenai pertanian secara luas. Pada tahapan ini juga diperkenalkan teknik pertanian berbasis hidroponik dengan sistem Wick, serta keuntungan teknik tersebut.

c. Pengenalan Sayur-Sayuran Organik

Kegiatan ini memperkenalkan sayur-sayuran organik yang dapat ditanam dan dijadikan nutrisi bagi penyandang DM.

\section{Pelaksanaan}

Setelah mengetahui berbagai teknk, media dan produk yang ada serta peluang yang bisa didapatkan, maka tahap selanjutnya adalah pelaksanaan. Sebelum kegiatan diberikan pembekalan materi teknik hidroponik dengan sistem Wick. Kegiatan ini dilaksanakan dalam 
https://journal.uwgm.ac.id/index.php/abdimasmahakam

E-ISSN: 2549-5755

Januari 2020, Vol. 4 No. 01

bentuk simulasi dalam mengaplikasikan teori-teori yang telah dipaparkan. Pelaksanaan ini meliputi beberapa kegiatan, antara lain:

a. Pembuatan Media Hidroponik. Kegiatan ini merupakan simulasi langsung pembuatan medium hidroponik dengan memanfaatkan lahan sempit dan menggunakan berbagai limbah seperti botol air bekas, kaleng bekas dan paralon. Barang-barang tersebut dirakit secara sederhana untuk dapat digunakan dalam teknik hidroponik.

b. Penanaman Sayuran Organik. Kegiatan penanaman ini dilakukan teknik penanaman yang efektif dan efisien. Sayuran ditanam pada media yang sederhana berupa kain flannel/sumbu, kerikil, arang sekam, dan pasir zeolit. Penanaman dimulai dari benih yang ditumbuhkan pada media tanam tersebut. Sumber nutrisi diberikan secara berkala sesuai dengan perbandingan larutan.

c. Bimbingan Intensif. Sebelum proses penanaman, dilakukan cara penyemaian bibit tanaman di wadah hingga tanaman siap untuk ditanam di media tanam. dan mengontrol medium yang digunakan masih baik dan melihat perkembangan sayur-sayuran yang ditanam.

Dalam pelaksanaan kegiatan digunakan metode berupa : 1) Metode ceramah dengan media dan alat bantu seperti power point, video animasi dan leaflet materi; 2) Metode tanya jawab untuk menggali keingintahuannya sebanyak-banyaknya tentang penjelasan komplikasi penyakit diabetes melitus dan nutrisi bagi penderita diabetes melitus serta teknik hidroponik beserta prospek dan peluang usaha secara hidroponik; dan 3) Metode demonstrasi untuk pengenalan dan melatih peserta dalam mempraktekkan materi pelatihan teknik budidaya dengan sistem hidroponik sederhana yakni sistem Wick. Setelah itu diikuti dengan demonstrasi mengenai metode hidroponik dan diakhiri dengan praktik mandiri oleh peserta. Bahan dan tanaman yang digunakan kemudian diserahkan kepada peserta untuk contoh.

Evaluasi dalam kegiatan ini dilaksanakan dalam tiga tahap, yaitu:

a. Selama proses kegiatan. Evaluasi pada tahap ini ditujukan untuk mengetahui tingkat pengetahuan, pemahaman para peserta disertai umpan balik berupa pertanyaan-pertanyaan dari para peserta undangan yang telah mendapatkan transfer pengetahuan terkait sistem pertanian hidroponik.

b. Tahap akhir kegiatan. Evaluasi pada akhir kegiatan ini dilakukan untuk mengukur keberhasilan dari seluruh program pelatihan. Adapun indikator keberhasilan dari kegiatan ini ditetapkan $80 \%$ peserta dalam kegiatan pelatihan ini dapat memahami tekhnik budidaya dengan sistem hidroponik. 
https://journal.uwgm.ac.id/index.php/abdimasmahakam

E-ISSN: 2549-5755

Januari 2020, Vol. 4 No. 01

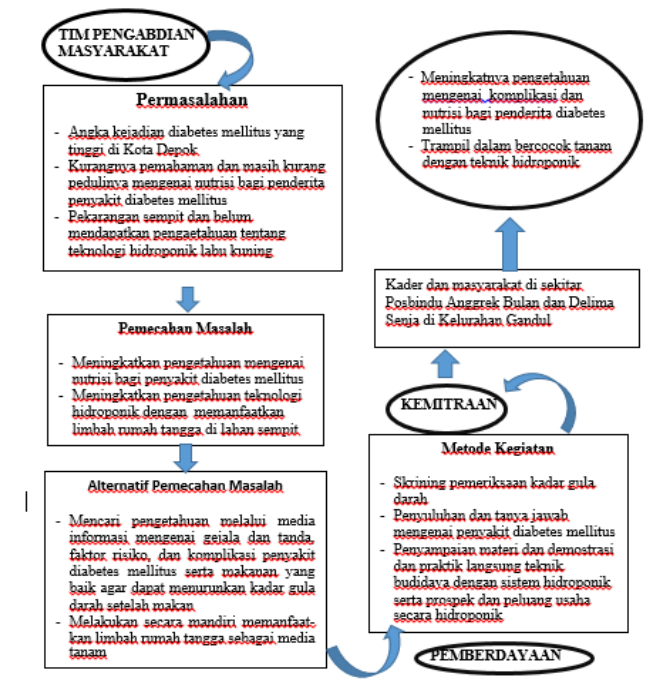

Bagan Skematis Metode Pelaksanaan Kegiatan

Sasaran pada kegiatan ini adalah ibu-ibu kader posbindu serta masyarakat yang anggota keluarganya memiliki penyandang DM. Sukerelawan yang ikut dalam kegiatan ini adalah mahasiswa Fakultas Kedokteran Tingkat IV yang ingin berpartisipasi untuk dapat mengaplikasikan Ilmu Kesehatan Masyarakat yang sudah didapatkannya.

Alat dan bahan yang dibutuhkan pada kegiatan ini adalah spanduk, ppt, leaflet, laptop, LCD, video dan kuesioner. Untuk demostrasi dan praktek teknik hidroponik yang dibutuhkan antara lain wadah/pot tanaman menggunakan Net Pot atau barang bekas seperti botol plastik, gelas plastik, kain flanel, rockwool/arang sekam, bibit sayuran, nutrisi AB mix, tusuk gigi, nampan plastik untuk tempat menyemai bibit.

\section{Hasil dan Pembahasan}

Kegiatan pengabdian kepada masyarakat ini telah dilaksanakan di RW 05 Kelurahan Gandul yang dihadiri 15 orang terdiri dari kader dan masyarakat sekitar. Berikut ini diuraikan hasil dari program kepada masyarakat tersebut.

Pada tahap persiapan dilakukan observasi lapangan ke tempat kediaman kader pada tanggal 19 Juli 2019 dengan melihat data posbindu terkait jumlah penyandang DM dan komplikasi yang sudah didapatkan dari penyandang serta melihat kondisi lingkungan, menentukkan lokasi pembuatan hidroponik. Kemudian kegiatan penggalian informasi terhadap masalah kesehatan terkait DM kepada kader secara langsung terutama pengetahuan mereka tentang nutrisi dalam menurunkan kadar gula darah. Focus Group Discussion (FGD) dengan beberapa kader untuk menggali informasi sebanyak-banyaknya, juga membahas berbagai persoalan kesehatan yang terjadi di masyarakat terkait penyakit diabetes melitus dan hidroponik. 


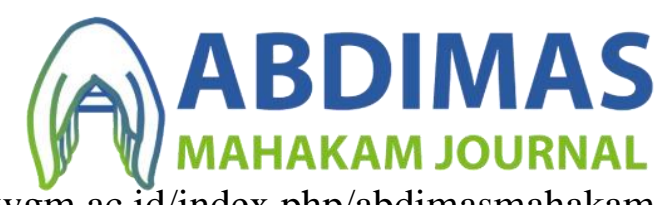

https://journal.uwgm.ac.id/index.php/abdimasmahakam

E-ISSN: 2549-5755

Januari 2020, Vol. 4 No. 01

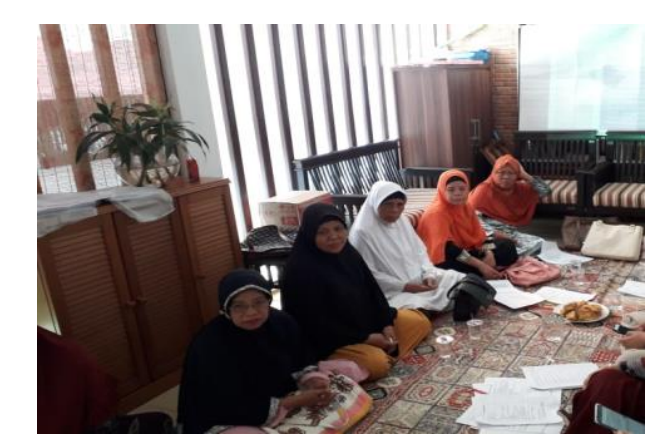

Gambar 2. Kegiatan Tahap Persiapan Kegiatan

Kegiatan pada tahap pengenalan dan penyuluhan kesehatan mengenai penyakit diabetes melitus baik komplikasi dan nutrisi bagi penyandang DM telah dilakukan pada tanggal 2 Agusus 2019 di Kediaman Ibu Andri sebagai kader posbindu. Kegiatan dilakukan dengan diskusi dan tanya jawab serta memberikan leaflet.
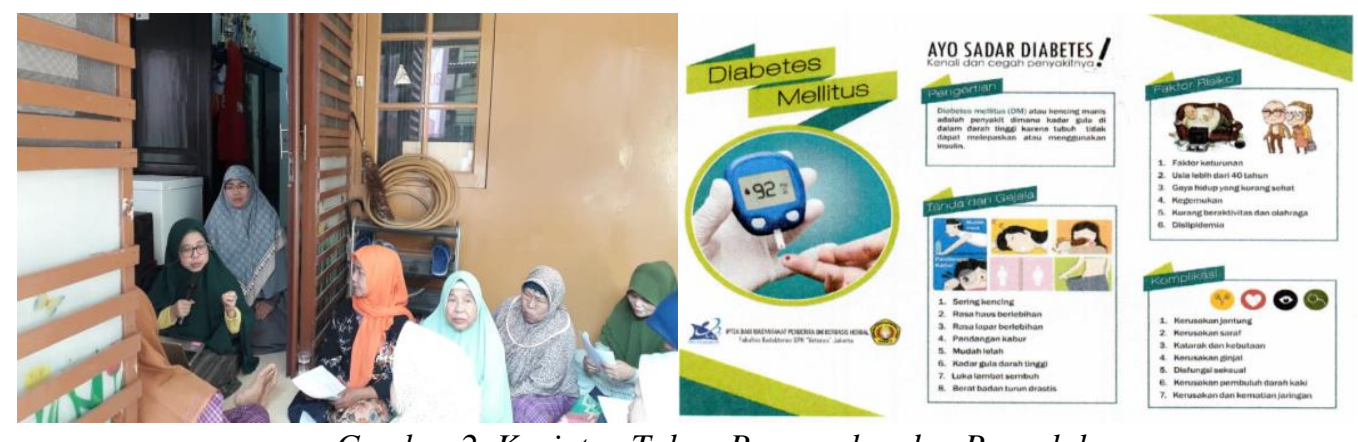

Gambar 2. Kegiatan Tahap Pengenalan dan Penyuluhan

Kegiatan tahap pelaksanaan telah dilakukan pada tanggal 3 Agustus 2019 di kediaman Bapak H.Dani Rt 11 RW 05. Pertama kegiatan yang dilakukan adalah ceramah dan diskusi serta Tanya jawab terkait pembekalan materi mengenai teknik hidroponik dengan sistem Wick. Sistem ini sangat sederhana bagi pemula dan untuk kondisi masyarakat memiliki keterbatasan lahan dan air, namun masyarakat disarankan tetap bercocok tanam di lingkungan sekitarnya agar minimal bisa mendukung ketahanan pangan secara mandiri, selain dapat memperindah lingkungan dan bagi yang menekuninya dengan serius akan mampu menjadi peluang wirausaha baru. Kemudian kegiatan dilanjutkan dengan demontrasi pembuatan media tanam dengan menggunakan barang bekas seperti botol plastik, ember atau gelas minuman plastik. Dalam hal ini disediakan juga set media tanam dengan menggunakan netpot, wadah baskom dan kain flanel. Selanjutnya pembuatan penyemaian bibit tanaman di atas rockwall, lalu pembuatan takaran medium nutrisi dari bahan kimia. Setelah pembekalan, peserta kader diminta praktek mandiri dengan bahan barang bekas yang dibawa selain set media hidroponik yang dibagikan. Sebelum dan sesudah pembakalan dan praktek hidroponik dilaksanakan pretest dan posttest. 


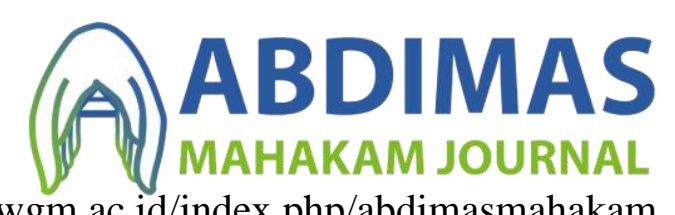

https://journal.uwgm.ac.id/index.php/abdimasmahakam

E-ISSN: 2549-5755

Januari 2020, Vol. 4 No. 01
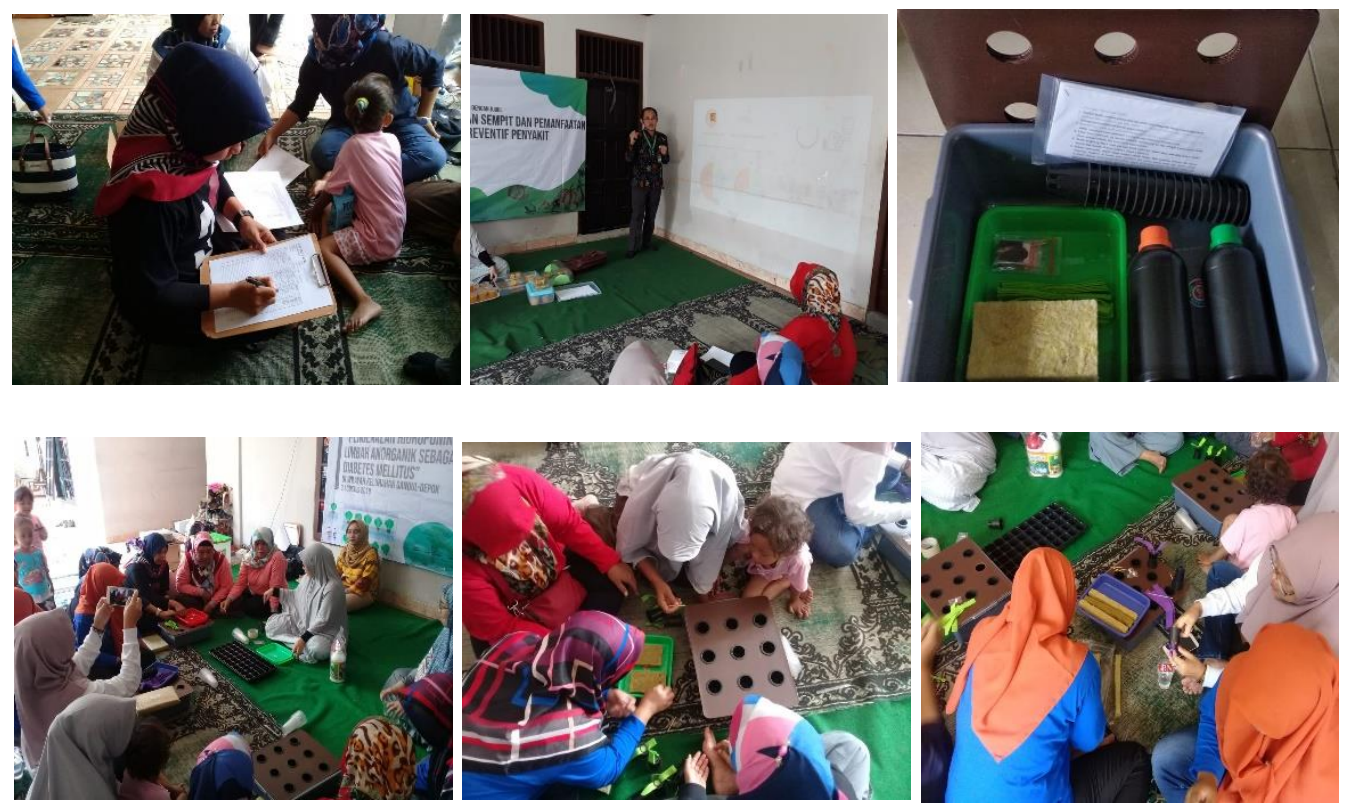

Gambar 4. Kegiatan Tahap pelaksanaan Teknik Hidroponik

Evaluasi kegiatan pengabdian dilakukan dengan cara yaitu menilai tingkat partisipasi kader yang jumlahnya mencapai 14 orang $(93,3 \%)$ dari total 15 orang kader. Evaluasi pemahaman peserta terhadap materi penyuluhan, dari hasil pretest dan posttest didapatkan peningkatan pengetahuan sekitar $80 \%$ dan peningkatan sikap positif kader menjadi $92,86 \%$ dari total peserta terhadap hidroponik. Dampak penyuluhan terlihat dari tahapan demi tahapan penyuluhan ini terlihat antusiasme kader dan terlihat diskusi semakin hidup lewat interaksi pada saat praktek budidaya hidroponik, serta membuat wadah tanaman dari barang bekas serta peserta menguasai permasalahan yang mendasar mengenai pemanfaatan lahan pekarangan, penyiapan media tanam untuk budidaya sayuran dalam pot yang menggunakan barang bekas.

Materi penyuluhan sesuai dengan Saptana Ashari dan Purwantini (2012) menyatakan bahwa hidroponik menjadi alternatif yang dapat digunakan untuk meningkatkan produktifitas tanaman terutama di lahan sempit. Hidroponik adalah budidaya menanam dengan memanfaatkan air tanpa menggunakan tanah seperti batu apung, kerikil, pasir, sabut kelapa, potongan kayu atau busa dengan menekankan pada pemenuhan kebutuhan nutrisi bagi tanaman. Guna media tanam tersebut untuk menyalurkan air nutrisi dan oksigen. Penggunaan air dengan metode hidroponik ini lebih sedikit daripada bercocok tanam dengan menggunakan media tanah (Indriasari, I.,2018). Hidroponik merupakan salah satu cara bercocok tanam yang memanfaatkan air sebagai media nutrisi yang akan langsung diserap oleh tanaman sebagai penunjang tumbuh tanaman; dapat diaplikasikan di perkotaan maupun di pedesaan yang hemat air dan tempat serta pemeliharaannya mudah dan dapat dipanen sepanjang tahun. Dengan teknologi hidroponik, masyarakat dapat memenuhi kebutuhan sayuran organik setiap harinya. Dengan pekarangan yang sempit masyarakat dapat memenuhi sumber vitamin dan mineral, contonya sawi, bayam, selada, kangkung, tomat, labu kuning, dan lain-lain (Repository IPB). 


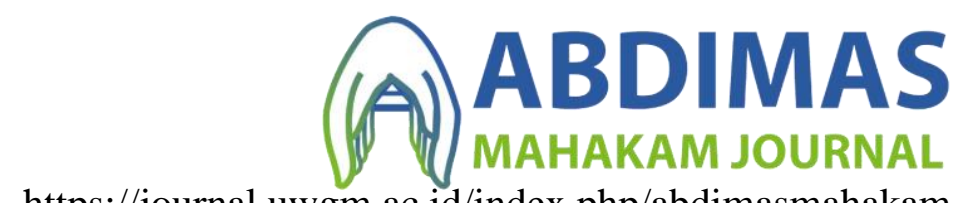

https://journal.uwgm.ac.id/index.php/abdimasmahakam

E-ISSN: 2549-5755

Januari 2020, Vol. 4 No. 01

\section{Simpulan dan rekomendasi}

Kegiatan pengabdian ini dapat menambah pengetahuan dan sikap serta ketrampilan kader tentang pentingnya pemanfaatan lahan pekarangan melalui penerapan konsep rumah pangan lestari untuk mendukung ketahanan pangan keluarga melalui bercocok tanam dengan teknik hidroponik. Kegiatan pengabdian ini meningkatkan kesadaran masyarakat untuk memanfaatkan barang bekas sebagai upaya mengurangi keberadaan sampah plastik lewat budidaya sayuran dalam pot.

\section{Ucapan Terima Kasih}

Atas terselesainya program pengabdian ini, penulis ingin mengucapkan terimakasih kepada Lembaga Penelitian dan Pengabdian Masyarakat UPN Veteran Jakarta yang telah mendanai program pengabdian kepada masyarakat. Tidak lupa penulis juga ingin mengucapkan terimakasih kepada seluruh ibu-ibu kader Posbindu RW 05 dan aparat RW 05 Kelurahan Gandul yang telah berperan aktif dalam pelaksanaan program. 
https://journal.uwgm.ac.id/index.php/abdimasmahakam

E-ISSN: 2549-5755

Januari 2020, Vol. 4 No. 01

\section{Daftar Pustaka}

Dinas Kesehatan Depok. (2018). Profil kesehatan Kota Depok Tahun 2018. Profil Kesehatan Kota Bukittinggi, (54), 38-74. https://doi.org/10.1016/j.ajog.2006.12.019

Kegiatan, B., Oleh, D., Ridhwan, M., Agung, H., \& Nugroho, C. (2007). Laporan Akhir

Program Kreativitas Mahasiswa Hidroponik Sebagai Penghasil Sayur-Sayuran Organik Dengan Media Limbah Rumah Tangga Di Desa Babakan, Kecamatan Darmaga.

Ashari, Saptana, dan T.B. Purwantini.(2012). Potensi dan prospek pemanfaatan lahan pekarangan untuk mendukung ketahanan pangan. Forum Penelitian Agro Ekonomi (30): $13-30$.

BPS kota Depok.(2014a). Statistik Daerah Kecamatan Cinere 2014. Badan Pusat Statistik Kota Depok: $\mathrm{x}+31$ hal.

BPS kota Depok. (2014b). Kecamatan Cinere dalam angka 2014: Cinere district in figures. Badan Pusat Statistik Kota Depok: ix + 65 hal.

Dinkes Depok. (2017). http://dinkes.depok.go.id/wp-content/uploads/PROFILKESEHATAN-KOTA-DEPOK-2017.pdf

Perkumpulan Endokrinologi Indonesia.(2015).Konsensus Pengelolaan dan Pencegahan Diabetes Mellitus Tipe 2 di Indonesia.PB.PERKENI

Dinas Kesehatan Depok. (2018). Profil kesehatan Kota Depok Tahun 2018. Profil Kesehatan Kota Bukittinggi, (54), 38-74. https://doi.org/10.1016/j.ajog.2006.12.019

D.,Ridhwan, M., Agung, H., \& Nugroho, C. (2007). Laporan Akhir Program Kreativitas Mahasiswa Hidroponik Sebagai Penghasil Sayur-Sayuran Organik Dengan Media Limbah Rumah Tangga Di Desa Babakan, Kecamatan Darmaga.

Roidah, I.S. (2014). Pemanfaatan Lahan Dengan Menggunakan Sistem Hidroponik. Jurnal Universitas Tulungagung Bonorowo. Vol. 1, No. 2, Tahun 2014 (online), diakses 7 Juni 2017. 